\title{
Expression of leukocyte integrins and tissue factor in mononuclear phagocytes
}

\author{
B. Nakstad*, T. Haugen*, O.H. Skjønsberg**, T. Lyberg*
}

Expression of leukocyte integrins and tissue factor in mononuclear phagocytes. B. Nakstad, T. Haugen, O.H. Skjønsberg, T. Lyberg. CERS Journals Ltd 1998.

ABSTRACT: Coagulation is intimately involved in the pathology of inflammation. The leukocyte $\beta_{2}$-integrins have several functions, including serving as receptors for coagulation factor $\mathrm{X}$ and fibrinogen. Tissue factor (TF) is a receptor for factor VII and a very potent trigger of coagulation. The intention of this study was to examine a possible coexpression of $\beta_{2}$-integrins $(\mathrm{CD11b} / \mathrm{CD18}$ and $\mathrm{CD11c} / \mathrm{CD18})$ and the procoagulant TF in alveolar macrophages (AM) and blood monocytes, i.e. cells of the same differentiation lineage.

The expression of $\beta_{2}$-integrins in human AM isolated by bronchoalveolar lavage and in blood monocytes was analysed by flow cytometry, whereas TF activity was analysed in a one-stage clotting assay.

In monocytes, TF activity, CD11b and CD11c expression were highly inducible by lipopolysaccharide (LPS), with a 13-, 19- and four-fold increase, respectively. In AM, TF and $\beta_{2}$-integrins were all constitutively expressed, but the expression could not be further enhanced by LPS stimulation. CD11b and CD11c expression varied inversely with the cell size of $\mathrm{AM}$, in contrast to TF activity which is known to be proportional to AM cell size.

In vitro expression of $\beta_{2}$-integrins and tissue factor in lipopolysaccharide-stimulated blood monocytes seems to be intimately coregulated, whereas the expression of these receptors in alveolar macrophages seems to be unresponsive to lipopolysaccharide. These results indicate that blood monocytes and alveolar macrophages have different roles and use different mechanisms in cell-induced fibrin formation.

Eur Respir J 1998; 12: 601-606.

The development of adult respiratory distress syndrome (ARDS), infant respiratory distress syndrome (IRDS) and septicaemia is known to be associated with pulmonary intravascular, interstitial and intra-alveolar deposition of fibrin [1]. The formation of fibrin during injury and inflammatory reactions, followed by its clearance during the repair process, is the result of a dynamic interplay between coagulant and fibrinolytic factors which amongst other cells are synthesized by peripheral blood monocytes, lung alveolar macrophages (AM) and lung interstitial macrophages [2-4]. Tissue factor (TF), which is produced by mononuclear phagocytes, is a receptor for coagulation factor VII [5] and plays an important role in the initiation of intravascular and extravascular coagulation leading to fibrin generation $[2,3]$. Owing to their expression of strong procoagulant (TF) activity, monocytes and AM represent foci for the deposition of fibrinogen and/or fibrin in vivo [6] and in vitro $[7,8]$. Binding of fibrinogen to specific receptors on blood monocytes has also been postulated to play a specific role in the differentiation of monocytes into macrophages [9]. Both monocytes and AM express $\beta_{2}$ integrins (CD11b/CD18 and CD11c/CD18) on the cell surface which, in addition to mediating intercellular adhesion [10], have been shown to bind fibrinogen and factor $\mathrm{X}$ [11-13]. Coordinated membrane expression of procoagulant activity (TF) and receptors for coagulation factors (CD11b/CD18 and CD11c/CD18) would facilitate fibrin
*Research Forum and **Dept of Pulmonary Medicine, Ullevaal University Hospital, Oslo, Norway.

Correspondence: B. Nakstad

Dept of Pediatrics

Ullevaal University Hospital

0407 Oslo

Norway

Fax: 4722118663

Keywords: Blood monocytes

flow cytometry

integrins

lung alveolar macrophages

tissue factor

Received: April 261997

Accepted after revision May 151998 deposition when plasma factors and cofactors are supplemented. It is not known, however, whether these molecules are presented in a concerted fashion on the cell surface or whether they are independently regulated. Blood monocytes and AM are both members of the same cell differentiation (monocyte) lineage, but they are normally exposed to a different local milieu. It was, therefore, of interest to compare their response to the biologically highly active stimulant lipopolysaccharide (LPS), which in vivo is a potential candidate for cell stimulation during systemic pathological conditions such as septicaemia, but also locally when micro-organisms are introduced via the respiratory tract. LPS is a bacterial product of the outer membrane of Gram-negative bacteria which exerts its effects both directly, but also indirectly via the release of proinflammatory cytokines such as tumour necrosis factor (TNF)- $\alpha$, interleukin (IL)-1 $\beta$ and IL-6. The intention of this study was, therefore, to compare the baseline expression of $\mathrm{TF}$ and $\beta_{2}$-integrins on blood monocytes and AM and to examine the changed expression induced by LPS challenge.

\section{Materials and methods}

\section{Bronchoalveolar lavage}

Bronchoalveolar lavage (BAL) was performed in healthy, nonsmoking volunteers with normal lung function 
(seven males and seven females, aged 26 \pm 3 yrs (mean \pm SEM)). A Pentax FB 15X (Asahi Optica Co., Tokyo, Japan) bronchoscope wedged in a segmental bronchus of the middle lobe was used and $50 \mathrm{~mL}(\times 3)$ of sterile $0.9 \%$ $\mathrm{NaCl}\left(37^{\circ} \mathrm{C}\right)$ was instilled. The lavage fluid was recovered by gentle suction and immediately cooled on crushed ice. The study was approved by the regional ethics committee.

\section{Alveolar macrophages}

AM were separated from BAL fluid by centrifugation at $800 \times \mathrm{g}$ for $7 \mathrm{~min}$. Cells were then washed twice $(300 \times \mathrm{g}$ for $5 \mathrm{~min}$ ) in phosphate buffered saline (PBS) and finally resuspended in endotoxin-free $\left(<50 \mathrm{pg} \cdot \mathrm{mL}^{-1}\right)$ cell culture medium (RPMI 1640; Gibco-Biocult, Paisley, UK) supplemented with $20 \%$ inactivated $\left(56^{\circ} \mathrm{C}, 30 \mathrm{~min}\right)$ foetal calf serum (Bio-Wittacker, Walkerswille, ML, USA) and seeded in 24-well tissue culture clusters (Costar, Cambridge, MA, USA) for TF analysis. Viability of cells was examined using the trypan blue exclusion technique. Differential counting was performed on cytospin preparations (Shandon cytospin 2, London, UK) and stained with a modified Giemsa technique (DiffQuick, Merz+Dade, Harleco, Philadelphia, PA, USA). For flow cytometric analysis cells were suspended and cultured in polystyrene tubes.

\section{Blood monocytes}

Monocytes were obtained from healthy, nonsmoking volunteers (three males and four females, aged 28 \pm 2 yrs (mean \pm Sem)) by Lymphoprep (Nycomed Pharma, Oslo, Norway) centrifugation and adherence to tissue culture clusters as described in a previous paper [14]. Using this technique monocytes adhere to the plastic surface, whereas lymphocytes are nonadherent and are consequently removed by washing.

\section{Experimental procedures}

Cell cultures of AM and monocytes were incubated at $37^{\circ} \mathrm{C}$ in humidified air with $5 \% \mathrm{CO}_{2}$ for different periods (up to $24 \mathrm{~h}$ ) in the absence and presence of LPS (lipopolysaccharide B from Escherichia coli 026: B6, Difco Laboratories, Detroit, MI, USA) (100 ng. $\left.\mathrm{mL}^{-1}\right)$. The choice of sampling times was based on preliminary studies for each parameter with seven to 10 different time points ranging 0-72 h illustrating the maximal response. LPS concentrations ranging $1 \mathrm{ng} \cdot \mathrm{mL}^{-1}-100 \mu \mathrm{g} \cdot \mathrm{mL}^{-1}$ were preliminarily analysed. The only concentration used in this study (100 $\left.\mathrm{ng} \cdot \mathrm{mL}^{-1}\right)$ was eventually chosen because it gave a close to maximal LPS response in monocytes in vitro as regards all of the studied parameters and this LPS concentration is likely to be obtained in plasma in severe endotoxaemia.

\section{Tissue factor assay}

AM (3-6 $\times 10^{5}$ cells $\cdot$ well $\left.^{-1}\right)$ and monocytes (1.0-1.5 $\times 10^{6}$ cells $\cdot$ well $\left.^{-1}\right)$ were handled as described above and, after incubation, the cells were scraped off with a rubber policeman, washed twice in saline, resuspended in $0.5 \mathrm{~mL}$
Veronal-buffered saline $(\mathrm{pH} 7.35)$ and frozen at $-20^{\circ} \mathrm{C}$. After thawing and manual homogenization, AM and monocyte homogenates were tested for TF activity [15] and total protein [16]. Reference curves for TF were prepared by dilution of a standard human brain TF preparation [17] arbitrarily chosen to contain $100 \mathrm{U} \cdot \mathrm{mL}^{-1}$. TF activity was expressed as $\mathrm{U} \cdot \mathrm{mg}$ cell protein $^{-1}$.

\section{Flow cytometry}

An aliquot of $50 \mu \mathrm{L}$ of AM suspension $\left(1-4 \times 10^{5}\right.$ cells) or whole blood was incubated for $30 \mathrm{~min}$ in the dark with either $20 \mu \mathrm{L}$ CD11b-specific (Becton Dickinson, Rutherford, NJ, USA) or $10 \mu \mathrm{L}$ CD11c-specific (Sigma, St Louis, MO, USA), monoclonal fluorescein-conjugated antibodies. After erythrocyte lysis (in the case of monocytes), cells were washed twice with $2 \mathrm{~mL}$ PBS and fixed in $0.5 \mathrm{~mL} 1 \%$ paraformaldehyde. Cell suspensions with $10 \mu \mathrm{L}$ of PBS served as controls. $\beta_{2}$-integrin expression was evaluated using a FACScan (Becton Dickinson) flow cytometer with an argon laser operating at $488 \mathrm{~nm}$. Mean fluorescence intensity (MFI) was calculated by measuring $5 \times 10^{3}(\mathrm{AM})$ or $1 \times 10^{4}$ (monocytes) events, using the PCLysys 1.0 software program (Becton Dickinson). Relative linear mean fluorescence intensity (RLMFI) was measured in arbitrary units and given as the ratio between specific and nonspecific (autofluorescence) linear fluorescence. Comparisons between gated areas of large, granulated macrophages and smaller, less granulated macrophages, were made as illustrated in figure $1 \mathrm{a}$.

\section{Statistics}

Results are expressed as mean \pm SEM. The Wilcoxon's rank sum test and signed rank test of paired data were used for estimating significance. A p-value $<0.05$ was considered statistically significant.

\section{Results}

The purity of the AM preparations used in these experiments was $92 \pm 2 \%$, whereas the proportion of lymphocytes was $6 \pm 2 \%$ and neutrophils was $2 \pm 1 \%$. The purity of the monocytes in the monolayered cultures was $>90 \%$ in every experiment, whereas lymphocytes represented the rest of the cell population. The viability of cells was always $>90 \%$ (92 $\pm 1 \%$ for AM and $95 \pm 1 \%$ for monocytes).

\section{CD11b expression in blood monocytes and alveolar mac- rophages}

Blood monocytes had a higher (two-fold, $\mathrm{p}<0.05$ ) basal CD11b expression than AM harvested by BAL (figs. 2a, 3a). Furthermore, monocytes had a significant potential to increase their CD11b expression (19-fold, $\mathrm{p}<0.001)$ after LPS stimulation; the peak CD11b expression was observed $2 \mathrm{~h}$ (fig. $3 \mathrm{a}$ ) after in vitro exposure to LPS. In contrast, AM could not be stimulated to increase their CD11b expression significantly above basal levels. Flow cytometric scatter plot-based separation (forward scatter versus 

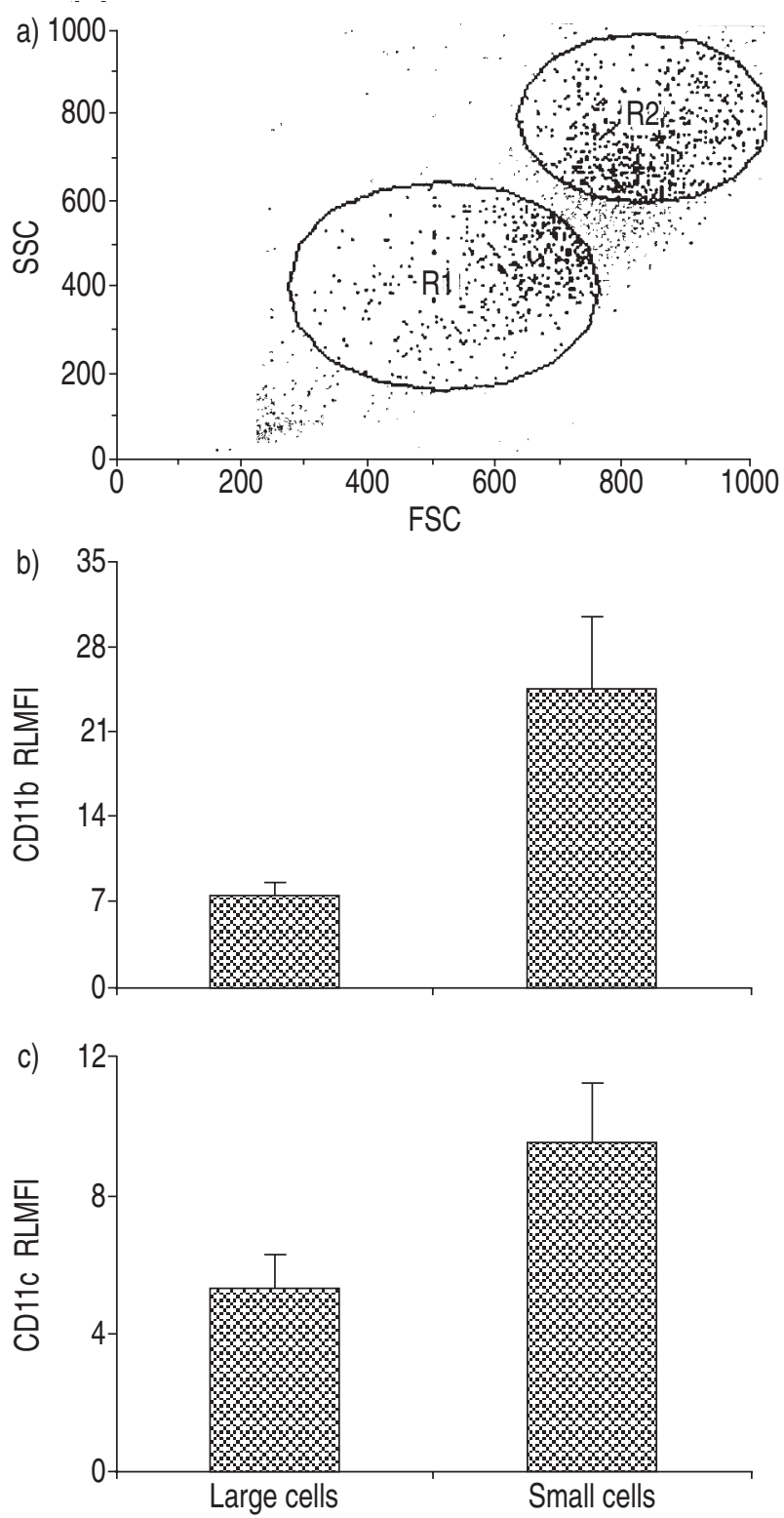

Fig. 1. - a) Forward-scatter (FSC) (size) versus side-scatter (SSC) (granularity) plot of lung alveolar macrophages (AM). Area R2 represents the larger and slightly more heavily granulated AM, whereas area $\mathrm{R} 1$ represents smaller and less granulated cells. b) CD11b expression of gated areas $\mathrm{R} 1$ and $\mathrm{R} 2 \mathrm{AM}$. Results are presented as mean+SEM $(\mathrm{n}=7)$. c) CD11c expression of gated areas R1 and R2 AM. Results are presented as mean $\pm \operatorname{SEM}(n=7)$. RLMFI: relative linear mean fluorescence intensity.

side scatter) of AM into subfractions (fig. 1a) showed that $\mathrm{CD} 11 \mathrm{~b}$ was most extensively expressed in the gated area R1 including AM which were smaller and less granulated than AM in the gated area R2 of larger size and higher granularity ( $\mathrm{p}<0.02$, fig. $1 b)$.

CD11c expression in blood monocytes and alveolar macrophages

No difference in basal CD11c expression was observed between AM and monocytes (figs. $2 \mathrm{~b}$ and $3 \mathrm{~b}$ ). As noted
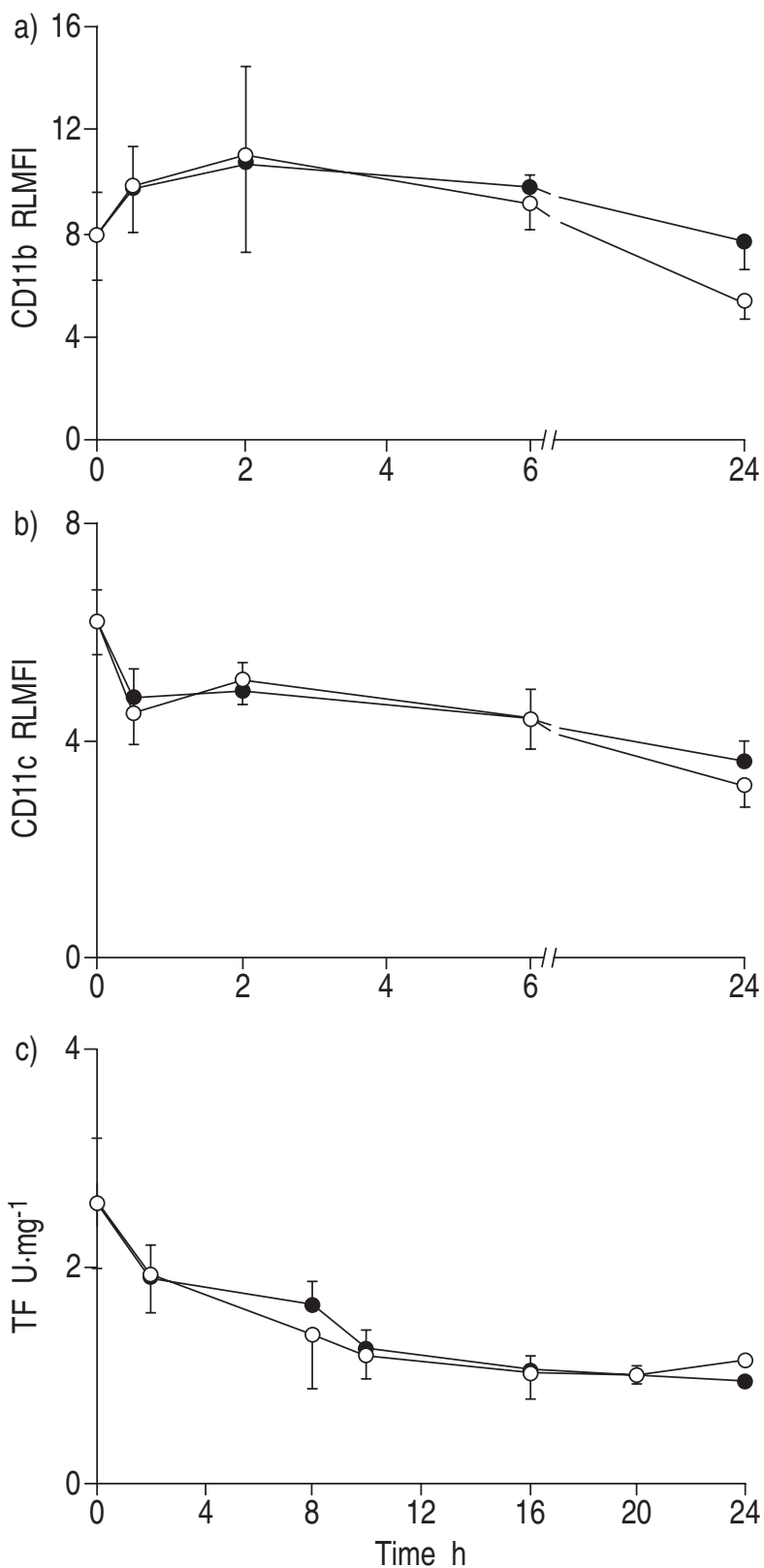

Fig. 2. - Time course for the expression of a) CD11b (n=7), b) CD11c $(n=7)$, and c) tissue factor (TF) activity $(n=7)$ in human lung alveolar macrophages stimulated by lipopolysaccharide (LPS; $0.1 \mu \mathrm{g} \cdot \mathrm{mL}^{-1}$ ). control; $\mathrm{O}$ : LPS-stimulated. RLMFI: relative linear mean fluorescence intensity.

for $\mathrm{CD} 11 \mathrm{~b}$, monocytes had a significant potential to increase their CD11c expression, i.e. a four-fold increase above their basal expression. The maximal CD11c expression appeared after 6-8 h (fig. 3b) of in vitro LPS stimulation. AM, however, could not be stimulated to increase their expression of CD11c. In fact, during in vitro culture the expression of CD11c in AM decreased (fig. 2b). Flow cytometric scatter plot-based separation (forward scatter versus side scatter) of AM into subfractions (fig. 1a) showed that CD11c was most extensively expressed in the gated area R1 including AM which were smaller and less granulated than AM in the gated area $\mathrm{R} 2$ of larger size and higher granularity $(\mathrm{p}<0.05$, fig. $1 \mathrm{c})$. 

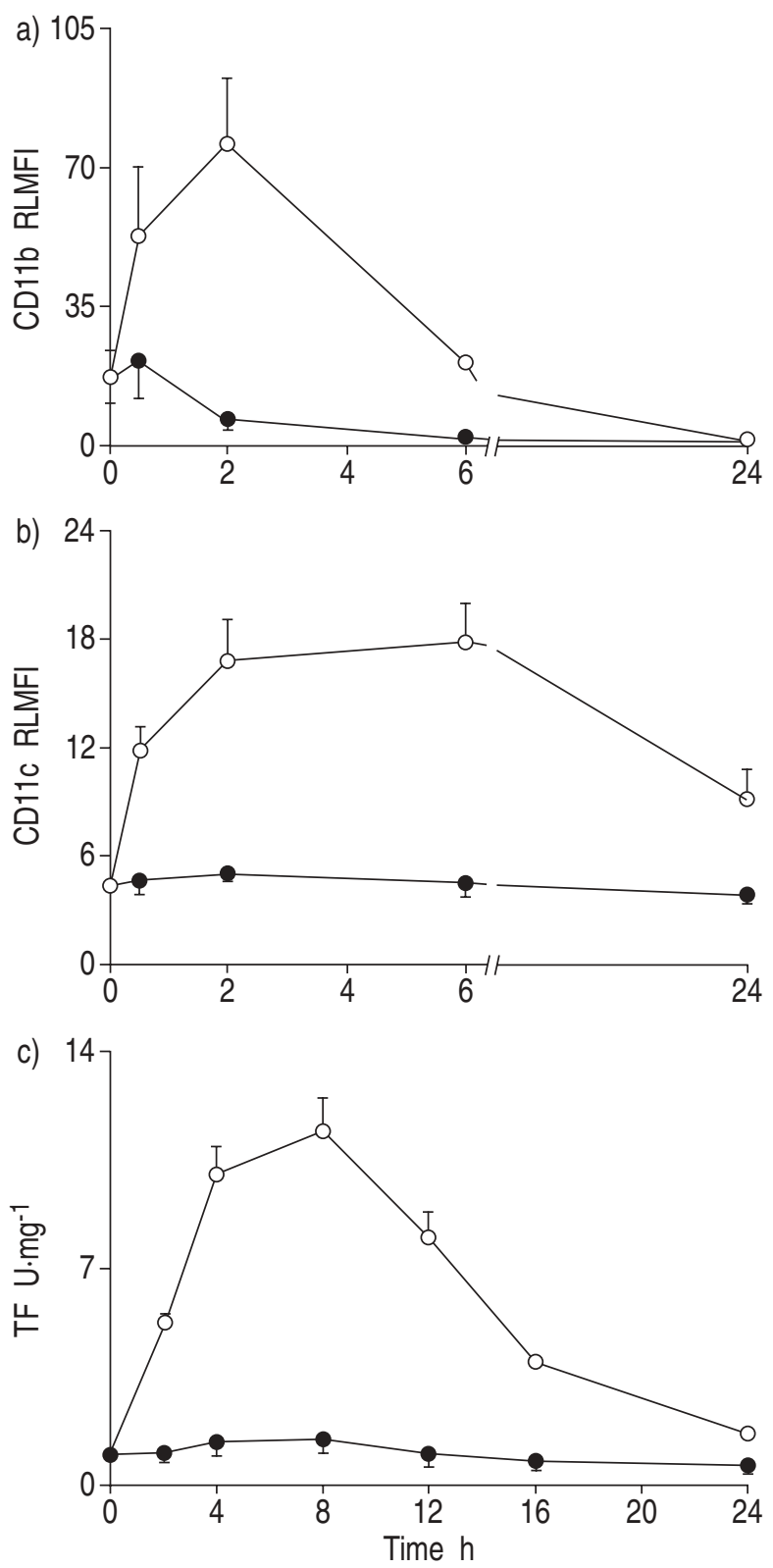

Fig. 3. - Time course for the expression of a) CD11b (n=7), b) CD11c $(n=7)$, and c) tissue factor (TF) activity $(n=7)$ in human blood monocytes stimulated by lipopolysaccharide (LPS) $\left(0.1 \mu \mathrm{g} \cdot \mathrm{mL}^{-1}\right)$. $\bullet$ : Control; 0 : LPS-stimulated. RLMFI: relative linear mean fluorescence intensity.

Tissue factor activity of blood monocytes and alveolar macrophages

Basal TF activity was significantly higher (three-fold, $\mathrm{p}<0.01$ ) in AM than in monocytes (figs. 2c and 3c) and monocytes had a highly significant $(\mathrm{p}<0.001)$ potential to increase the TF activity after LPS stimulation (fig. 3c). Maximally, a 13-fold increased expression of TF was noted and the maximal activity of TF was observed after 6-8 $\mathrm{h}$ of in vitro LPS stimulation. AM could not be induced to increase their expression of TF activity and during in vitro culture their activity decreased.

\section{Discussion}

In the present study we demonstrated an inducible coexpression of procoagulant activity (TF) and the $\beta_{2}$-integrin receptors CD11b/CD18 and CD11c/CD18 in human blood monocytes, whereas in AM a constitutive, noninducible synthesis and expression of all three molecules were observed. Both monocytes and AM synthesize TF [2, 3, 14] and are also able to produce and bind coagulation factor VII $[3,18,19]$. The complex of TF and factor VII initiates the cellular assembly of the prothrombinase complex [20], by which prothrombin is converted to thrombin [18]. The leukocyte $\beta_{2}$-integrins $\mathrm{CD} 11 \mathrm{~b} / \mathrm{CD} 18$ and $\mathrm{CD} 11 \mathrm{c} / \mathrm{CD} 18$ mediate a variety of functions which are upregulated when the cell is activated [11, 12]. At least one of these functions is associated with new epitopes that bind fibrinogen and coagulation factor $X$ [21]. The binding of factor $X$ to CD11b has been shown to be followed by a proteolytic activation step converting factor $\mathrm{X}$ to its active form $\mathrm{Xa}$ [13].

In contrast to monocytes, AM were fairly unresponsive to stimulation by LPS in vitro. The ability of monocytes to increase their procoagulant activity after LPS stimulation is an important factor in septicaemia and could explain most of the coagulation aberrations and thrombotic complications associated with this disorder. The ability of monocytes to increase rapidly the expression of CD11b and CD11c indicates that these cells are endowed with a fast integrin-associated system for pericellular fibrin formation in addition to the slower TF-driven system. Mutual interactions and interplay between these systems are highly probable, but the relative importance of each of these pathways is not known in detail. As demonstrated in other reports [22, 23], when monocytes are activated, CD11b/CD18 and CD11c/CD18 may be translocated from intracellular storage pools to the cell membrane, where they are expressed within a short time to reach maximal expression, as shown in this paper, within $2 \mathrm{~h}$ after LPS stimulation. Increased TF expression, in contrast, is dependent on de novo protein synthesis and therefore, requires more time.

In contrast to monocytes, AM apparently lack both the fast and the delayed phase of LPS-induced procoagulant activities. This could be a result of loss of properties, i.e. response to stimulation, in the process of differentiation from monocytes to AM. Different theories about the origin of AM have emerged. One theory considers them to be end cells, derived from monocytes and incapable of division in the steady state [24]. According to a second theory a bone marrow-derived cell population in the interstitium of the lung produces pulmonary AM by local division and maturation [25]. Lastly, a theory on monocytes maturing in the lung capillaries and final mitosis in the alveoli has been proposed [26]. However, irrespective of origin, but owing to their distribution to the pulmonary air-fluid interface, AM may be exposed to several inhaled stimulants that may prime and activate the cells, inducing a permanent, unresponsive state as indicated for CD11b, CD11c and TF responses after LPS stimulation in vitro. Nevertheless, AM show a constitutive, high expression of both TF and $\mathrm{CD} 11 \mathrm{~b}$, which means that pericellular fibrin formation may take place when the necessary coagulation factors become available. The procoagulant potential of AM may be considered as a defence mechanism which becomes operable when the alveolocapillary membrane permeability is increased to a degree where coagulation factors can leak from blood plasma to the alveoli.

There seems to be an inverse distribution of $\beta_{2}$-integrins and TF activity between subfractions of AM which does 
not fit the hypothesis of a closely regulated expression of these receptors. TF activity in AM has been shown to be inversely proportional to cell buoyant density [14], whereas the expression of CD11b/CD18 and CD11c/CD18 seems to be proportional to AM density, as judged both by AM distribution in a flow cytometric forward versus side scatter plot (this study) and by direct examination of Percollseparated subfractions (T. Haugen et al., unpublished data). The skewed distribution of CD11b/CD18 and CD11c/ CD18 amongst subfractions of AM may also reflect that monocytes turn on the expression of these adhesion molecules in the process of their migration from the vasculature to become AM and that the same molecules are downregulated during the further differentiation process of AM. The importance of CD11b-induced coagulation thus probably decreases as AM mature, while the role of the TF-driven system is maintained or even enhanced, in line with earlier observations that TF represents a differentiation marker for mononuclear phagocytes [27, 28] and, thus, $\mathrm{TF}$ is maximally expressed in the most mature AM.

The binding of factor $\mathrm{X}$ and fibrinogen to monocytes and $\mathrm{AM}$ is probably, to a large extent, mediated by CD11b/CD18 [11, 12]. However, our group has previously reported the presence of another integrin on monocytes and AM, a glycoprotein (GP)IIb/IIIa-like $\beta_{3}$-integrin [29]. The role of this integrin in mononuclear phagocyteassociated fibrinogen binding and fibrin generation is not yet settled. Still another integrin is interesting when coregulation of integrin receptors and procoagulant activity is discussed. It has been shown that ligand engagement of a $\beta_{1}$-integrin $\left(\alpha_{4}\right.$ or $\left.\beta_{1}\right)$ may induce high levels of TF expression in mononuclear phagocytes [30].

Alveolar fibrin deposition seems to be a prominent feature in diffuse alveolar damage, owing to the presence of active procoagulants [31] and the increased alveolocapillary leak of clotting factors [32]. Together with a persistent abnormality of fibrin clearance in the alveolar compartment during evolving diffuse alveolar damage [33, 34], this may explain the formation of hyaline membranes on bronchoalveolar surfaces in respiratory distress syndrome [35]. Fibrin, especially when it is crosslinked to fibronectin, and fibrinopeptides, provides a chemotactic stimulus for fibroblast recruitment as well as a provisional matrix for fibroblast adhesion and replication [36, 37]. Fibroblast ingrowth into such fibrin deposits may have important consequences for the development of pulmonary fibrosis.

In conclusion, the potential of monocytes and alveolar macrophages to stimulate fibrin deposition in diseased lung tissue may act indirectly as a stimulant for the development of pulmonary hyaline membrane deposition and fibrosis development in respiratory distress syndrome. In blood, lipopolysaccharide stimulation induces an acute upregulation of coagulation promoting receptors in monocytes, whereas within the respiratory lumen alveolar macrophages represent a constitutive and lipopolysaccharide-independent coagulation potential which comes into function when the permeability of the alveolocapillary membrane is increased.

\section{References}

1. Zapol WM, Trelstad RL, Coffey JW. Pulmonary fibrosis in severe acute respiratory failure. Am Rev Respir Dis 1979; 119: 547-554.
2. Lyberg T. Clinical significance of increased thromboplastin activity on the monocyte surface. A brief review. Haemostasis 1984; 14: 430-439.

3. Tsao BP, Fair DS, Curtiss LK, Edgington TS. Monocytes can be induced by lipopolysaccharide-triggered T-lymphocytes to express functional factor VII/VIIa protease activity. J Exp Med 1984; 159: 1042-1057.

4. Chapman HA, Bertozzi P, Reilly JJ. Role of enzymes mediating thrombosis and thrombolysis in lung disease. Chest 1988; 93: 1256-1263.

5. Rottingen JA, Enden T, Camerer E, Iversen JG, Prydz H. Binding of human factor VIIa to tissue factor induces cytosolic $\mathrm{Ca}^{2+}$ signals in $\mathrm{J} 82$ cells, transfected COS-1 cells, Madin-Darby canine kidney cells and in human endothelial cells induced to synthesize tissue factor. $J$ Biol Chem 1995; 270: 4650-4660.

6. Hopper KE, Geczy CL, Davies WA. A mechanism of migration inhibition in delayed-type hypersensitivity reactions. I. Fibrin deposition on the surface of elicited peritoneal macrophages in vivo. J Immunol 1981; 126: 1052-1058.

7. Shelley WB, Juhlin L. Induction of fibrin thrombi by monocytes. Nature 1977; 270: 343-344.

8. Rajagopolan S, Pizzo SV. Characterization of murine peritoneal macrophage receptors for fibrin(ogen) degradation products. Blood 1986; 67: 1224-1228.

9. Akiyama Y, Griffith R, Miller P, et al. Effects of adherence, activation and distinct serum proteins on the in vitro human monocyte maturation process. J Leukocyte Biol 1988; 3: 224-231.

10. Hynes RO. Integrins. A family of cell surface receptors. Cell 1987; 48: 549-554.

11. Trezzini C, Jungi TW, Kuhnert P, Peterhans E. Fibrinogen association with human monocytes: evidence for constitutive expression of fibrinogen receptors and for involvement of MAC-1 (CD18, CR23) in the binding. Biochem Biophys Res Commun 1988; 156: 477-484.

12. Altieri DC, Edgington TS. The saturable high affinity association of factor $\mathrm{X}$ to ADP stimulated monocytes defines a novel function of the Mac-1 receptor. $J$ Biol Chem 1988; 263: 7007-7015.

13. Altieri DC, Morrissey JH, Edgington TS. Adhesive receptor Mac-1 coordinated the activation of factor X on stimulated cells of monocytic and myeloid differentiation: an alternative initiation of the coagulation protease cascade. Proc Natl Acad Sci USA 1988; 85: 7462-7466.

14. Nakstad B, Boye NP, Lyberg T. Procoagulant activities in human alveolar macrophages. Eur Respir J 1987; 71: 459-471.

15. Hvatum M, Prydz H. Studies on tissue thromboplastin. I. Solubilization with deoxycholate. Biochim Biophys Acta 1966; 130: 92-101.

16. Markwell MAK, Haas SM, Bieber LL, Tolbert NE. A modification of the Lowry procedure to simplify protein determination in membrane and lipoprotein samples. Anal Biochem 1978; 87: 206-210.

17. Hjort PF. Intermediate reactions in the coagulation of blood with tissue thromboplastin. Scand J Clin Lab Invest 1957; 9: Suppl. 27, 57-61.

18. Broze GJ. Binding of human factor VII and VIIa to monocytes. J Clin Invest 1982; 70: 526-535.

19. Chapman HA, Fair DS, Allen CL, Stone OL. Human alveolar macrophages synthesize factor VII in vitro. Possible role in interstitial lung disease. J Clin Invest 1985; 755: 2030-2037.

20. Tracy PB, Eide LL, Mann KG. Human prothrombinase complex assembly and function of isolated peripheral 
blood cell populations. J Biol Chem 1985; 260: 2119 2124.

21. Elemer GS, Edgington TS. Two independent sets of monoclonal antibodies define neoepitopes linked to soluble ligand binding and leukocyte adhesion functions of activated alpha-m beta-2. Circ Res 1994; 755: 165171.

22. Patarroyo M, Gahmberg CG. Phorbol 12,13-dibutyrate enhances lateral redistribution of membrane glycoproteins in human blood lymphocytes. Eur J Immunol 1984; 9: 781-787.

23. Schlieffenbaun B, Moser R, Patarroyo M, Fehr J. The cell surface glycoprotein Mac-1 (CD11b/CD18) mediates neutrophil adhesion and modulates degranulation independently of its quantitive cell surface expression. $J$ Immunol 1989; 142: 3537-3545.

24. Godleski JJ, Brain JD. The origin of alveolar macrophages in mouse radiation chimeras. J Exp Med 1972; 136: 630-643.

25. Bowden D, Adamson W, Grantham W, Wyatt JP. Origin of the lung macrophage: evidence derived from radiation injury. Arch Pathol 1969; 88: 540-546.

26. Masse R, Fritsch P, Nolibe D, Lafuma J, Chretien J. Cytokinetic study of the alveolar macrophage renewal in rats. In: Pulmonary Macrophages and Epithelial Cells. ERDA Symp Ser 1977; 43: 859-865.

27. Lyberg T, Ivhed I, Prydz H, Nilsson K. Thromboplastin as a marker for monocyte differentiation. Br J Haematol 1983; 53: 327-335.

28. Stephens AC, Zheng RQH, Bedford AR, Levin M, Rivers RPA. Production of tissue factor by monocyte progenitor cells. Thromb Res 1994; 76: 33-45.
29. Nakstad B, Lyberg T. Characterization of cytoadhesion molecules on human monocytes and tissue macrophages. Thromb Res 1990; 60: 43-54.

30. Fan ST, Mackman N, Cui MZ, Edgington TS. Integrin regulation of an inflammatory gene. Direct induction of the tissue factor promotor by engagement of beta 1 or alpha 4 integrin chains. J Immunol 1995; 154: 3266-3274.

31. Idell S, Gonzales K, Bradford $\mathrm{H}$, et al. Procoagulant activity in bronchoalveolar lavage in the adult respiratory distress syndrome. Am Rev Respir Dis 1987; 136: 14661474.

32. Dvorak HF, Seeger DR, Dvorak AM, Harvey VS, McDonaugh J. Regulation of extravascular coagulation by microvascular permeability. Science 1985; 227: 1059-1061.

33. Idell S, James KK, Levin EG, et al. Local abnormalities in coagulation and fibrinolytic pathways predispose to alveolar fibrin deposition in the adult respiratory distress syndrome. J Clin Invest 1989; 84: 695-705.

34. Seeger W, Grube C, Gunther A. Proteolytic cleavage of fibrinogen: amplification of its surfactant inhibitory capacity. Am J Respir Cell Mol Biol 1993; 9: 239-247.

35. Chapman HA, Bertozzi P, Reilly J. Role of enzymes mediating thrombosis and thrombolysis in lung disease. Chest 1988; 93: 1256-1263.

36. Rennard SI, Hunninghake GW, Bitterman PB, Crystal RG. Production of fibronectin by the human alveolar macrophage: mechanism for the recruitment of fibroblasts to sites of tissue injury in the interstitial lung diseases. Proc Natl Acad Sci USA 1981; 78: 7147-7151.

37. Gray AJ, Bishop JE, Reeves JT, Laurent GJ. A $\alpha$ and B $\beta$ chains of fibrinogen stimulate proliferation of human fibroblasts. J Cell Sci 1993; 104: 409-413. 